\title{
Metastasis-associated in colon cancer 1: A promising biomarker for the metastasis and prognosis of colorectal cancer (Review)
}

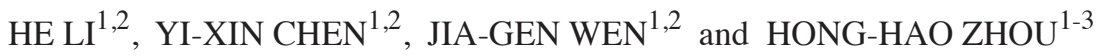 \\ ${ }^{1}$ Department of Clinical Pharmacology, Xiangya Hospital, Central South University, Changsha, Hunan 410008; \\ ${ }^{2}$ Institute of Clinical Pharmacology, Hunan Key Laboratory of Pharmacogenetics, Central South University, \\ Changsha, Hunan 410078; ${ }^{3}$ Hunan Province Cooperation Innovation Center for Molecular Target New Drug Study, \\ Hengyang, Hunan 421001, P.R. China
}

Received September 22, 2015; Accepted January 10, 2017

DOI: $10.3892 / \mathrm{ol} .2017 .6670$

\begin{abstract}
Colorectal cancer (CRC) is the fourth most frequent type of malignancy in the world. Metastasis accounts for $>90 \%$ mortalities in patients with CRC. The metastasis-associated in colon cancer 1 (MACC1) gene has been identified as a novel biomarker for the prediction of metastasis and disease prognosis, particularly for patients with early-stage disease. Previous clinical studies demonstrated that MACC1 expression and polymorphisms in CRC tissues were indicators of metastasis, and that circulating transcripts in plasma were also significantly associated with the survival of patients. The present review describes the use of MACC1 beyond its utility in the clinic. By elucidating the upstream and downstream signal pathways of MACC1, the well-known mechanisms of MACC1-mediated cell proliferation, invasion, migration and epithelial-mesenchymal transition (EMT) are summarized, as well as the potential signaling pathways. Furthermore, the underlying mechanisms by which the overexpression of MACC1 causes cisplatin resistance are emphasized.
\end{abstract}

\section{Contents}

1. Introduction

2. MACC1 is a novel biomarker for metastasis prediction and disease prognosis

3. Potential mechanisms of cell proliferation, invasion and migration induced by MACC1 in CRC cell cultures

4. Conclusions

Correspondence to: Professor Hong-Hao Zhou, Institute of Clinical Pharmacology, Hunan Key Laboratory of Pharmacogenetics, Central South University, 110 Xiangya Road, Yuelu, Changsha, Hunan 410078, P.R. China

E-mail: hhzhou2003@163.com

Key words: metastasis-associated in colon cancer 1, colorectal cancer, metastasis, biomarker, mechanism

\section{Introduction}

Colorectal cancer (CRC) is the fourth most frequent type of malignancy in the world (1). According to data collected by several authorities, including the National Cancer Institute and the National Center for Health Statistics, it was estimated that there would be 136,830 new cases of CRC and 50,310 moralities from CRC in 2014. In the United States, CRC represents $8.2 \%$ of all new cases of cancer and $8.6 \%$ of all cancer-associated mortalities.

Metastasis is the most lethal characteristic of CRC, accounting for $90 \%$ of the moralities of patients with colon cancer. The 5-year survival rates of patients with early-stage disease are up to $90 \%$, but the 5-year survival rates of patients with distant metastasis drop to $10 \%$. In addition, the metastatic dissemination of primary tumors is a pivotal cause for the failure of treatment $(2,3)$. However, there is currently no molecular marker to predict the possibility of CRC metastasis in an early and precise manner $(4,5)$.

Metastasis-associated in colon cancer 1 (MACC1), first identified by Stein et al (6) in 2009, is located on human chromosome 7 (7p21.1) at 20,146,776 to $20,223,538$ (76,762 bp) on the minus strand, and harbors 7 exons and 6 introns. At present, five splice variants have been revealed in different types of tissue (7). In addition, the topathological description of the gene was identified by applying a combination of fold recognition and homology modeling algorithms. The results showed that the protein contains four domains, namely, ZU5, SRC Homology 3 Domain (SH3) and two C-terminal death domains (DD) (8). The SH3 domain and SH3 binding motif are responsible for the biological function of the protein. The lack of SH3 domain or the proline-rich motif SH3 binding motif will lead to the loss of the Met gene, which is a transcriptional target of MACC1 (6). The ZU5 domain is comprised of two $\beta$-sheets and is known to mediate protein-protein interactions (8-10). The unique double DD architecture may trigger apoptosis $(8,11)$.

Stein et al (6) detected MACC1 mRNA expression levels in primary colon cancer. Based on the different MACC1 mRNA expression levels, the negative and positive predictions of metachronous distant metastases were corrected to 80 and $74 \%$, respectively. The evidence suggested that MACC1 may serve 
as a novel biomarker for metastasis prediction and disease prognosis, particularly for early-stage patients. Subsequently, MACC1 was also identified as the biomarker in other types of solid cancer, including gastric (12-18), lung (19-24) and breast (25-27) cancer, hepatocellular carcinoma (HCC) (28-38), ovarian cancer (39-41), renal carcinoma $(42,43)$, glioma $(44,45)$, gallbladder cancer $(46,47)$, tongue squamous cell carcinoma (48), osteosarcoma $(49,50)$, esophageal cancer $(51,52)$, nasopharyngeal carcinoma (NPC) (53), pancreatic cancer (54), hilar cholangiocarcinoma (55), salivary adenoid cystic carcinoma (56) and cervical cancer (57) (Table I).

The present review summarizes the current studies of MACC1 in CRC (Table II) and highlights the importance of MACC1 in the prediction of therapy response and the decision of therapeutic strategy (58-70). In addition, the present review highlights the previously found mechanisms of MACC1-mediated cell proliferation, invasion, migration and epithelial-mesenchymal transition (EMT) (Table III), and the regulation of MACC1 in CRC (Fig. 1).

\section{MACC1 is a novel biomarker for metastasis prediction and disease prognosis}

MACC1 expression in CRC. Through the examination of MACC1 mRNA expression levels in colon mucosa, normal liver, adenoma, primary tumors and distant metastasis, a previous study illustrated that more MACC1 mRNA was expressed in malignant tissue compared with normal tissue and adenoma $(\mathrm{P}<0.0001)$. Comparatively, tumors with metachronous metastasis expressed significantly higher levels of MACC1 mRNA compared with those that did not metastasize $(\mathrm{P}<0.0001)$. More pivotally, the 5-year survival rates of patients with high and low MACC1 mRNA expression were 15 and $80 \%$, respectively, indicating that MACC1 expression was an independent prognostic marker for colon cancer metastasis (6). Subsequently, the relevance of MACC1 expression to disease prognosis was also corroborated (58). In a clinical study with $52 \mathrm{CRC}$ tumor samples available, it was revealed that MACC1 expression was significantly correlated with peritoneal dissemination $(\mathrm{P}=0.042)$ and the stage of tumor node metastasis classification ( $\mathrm{P}=0.007)$. Recently, Koelzer et al further verified MACC1 expression as a predictive biomarker in a retrospective cohort study (67).

In addition, by examining MACC1 copy numbers and mRNA expression levels of 103 metastatic CRC tissues, it was confirmed that MACC1 expression was significantly correlated with colon cancer metastasis (71). Furthermore, the results of another study suggested that MACC1 expression was more than a prognostic marker for colon cancer metastasis, as it was also revealed to be associated with the recurrence of CRC (72), as confirmed by Nitsche et al (73) in 2012. According to individualized risk assessment of fresh frozen colon cancer tissue from 232 complete tumor resection patients with Union for International Cancer Control stage II disease, it was verified that the risk of cancer recurrence was markedly associated with an increased expression of MACC1 $(\mathrm{P}<0.001)$, independent of other biomarkers such as the mutation of KRAS proto-oncogene (73). Notably, MACC1 was the only independent parameter for recurrence prediction (hazard ratio, 6.2; $\mathrm{P}<0.001$ ) in $\mathrm{CRC}$ liver metastases (62).
In addition, MACC1 was revealed to be an independent biomarker for post-operative liver metastasis in patients with colon cancer (70).

To overcome the inherent limitation of obtaining tumor tissue via an invasive method, Stein et al (61) described a non-invasive assay for the quantification of MACC1 transcripts in the plasma of 312 patients with CRC. The results of the aforementioned study demonstrated that MACC1 transcript levels in plasma increased in patients with all stages of cancer in comparison with tumor-free volunteers. Similar to findings in the tumor tissues, high MACC1 levels in the plasma were also correlated with unfavorable survival $(\mathrm{P}<0.0001)$. Qualitative studies have demonstrated that the alterations in DNA and RNA extracted from the plasma of patients are similar to the alterations of primary tumor nucleic acids, meaning that tumor cells may be the origin of plasma or serum nucleic acids $(74,75)$. In addition, numerous studies verified the clinical value of extracellular RNA in plasma from patients with cancer (76-82), and the extracellular RNA in plasma was also revealed to be protected in a multiparticle complex and was actively released by tumor cells (83). Thus, it was hypothesized that MACC1 transcripts in plasma were released from tumor cells in a protected manner, and circulating MACC1 transcripts in plasma may be a prognostic indicator for the survival and metastasis of patients with CRC. The association between MACC1 status in the blood and patient prognosis requires additional investigation in a larger clinical study.

MACC1 polymorphisms in CRC. Lang et al (59) firstly investigated the potential association between single nucleotide polymorphisms (SNPs) of MACC1 and the survival of patients with colon cancer. A total of 318 patients with CRC were enrolled. A total of 6 tag SNPs (rs1990172, rs3114446, rs10275612, rs3095007, rs3095009 and rs7780032), representing the majority of the common variants of the MACC1 locus, were genotyped. However, only the carriers of SNP rs1990172 were revealed to exhibit an association with a significantly decreased overall survival (additive hazard ratio, $1.38 ; 95 \%$ CI, $1.05-1.82 ; \mathrm{P}=0.023$ ). The results of the aforementioned study indicated that SNP rs1990172 was a potential predictor for reduced overall survival in patients with CRC. Additionally, Schmid et al (60) sequenced the coding exons of MACC1 in 154 colorectal tumors (stages I, II and III) and found three MACC1 SNPs (rs4721888, L31V; rs975263, S515L; rs3735615, R804T) in the coding region. In addition, it was revealed that patients who were SNP rs975263 carriers, $<60$ years old, with stage I or II disease, exhibited an increased risk of shorter metastasis-free survival. However, none of the three SNPs were associated with clinicopathological parameters or the survival of the patients. In additional studies, the two SNPs (rs1990172 and rs975263) were associated with the clinical outcome of patients with HER2-positive breast cancer, and the recurrence and overall survival of patients with HCC undergoing liver transplantation $(26,84)$.

However, the focus of the majority of the aforementioned studies was CRC tissue. It is difficult to reflect disease progression and response to therapy using a single type of tissue sample or a single time point (85). Circulating tumor DNA (ctDNA) was revealed to be positively correlated with tumor progression (86). In addition, ctDNA was suggested to be 
Table I. Correlation of metastasis-associated in colon cancer 1 to clinical parameters in solid cancer types except colorectal cancer (in studies published from 2013 onwards).

\begin{tabular}{|c|c|c|c|c|c|}
\hline Tumor entity & $\begin{array}{l}\text { Sample } \\
\text { type }\end{array}$ & $\mathrm{n}$ & Method & Correlation to clinical parameters & (Refs.) \\
\hline \multirow{7}{*}{$\mathrm{GC}$} & Tumors & 436 & $\mathrm{IHC}$ & Invasion, metastasis, TNM stage and 5-year survival & $(15)$ \\
\hline & Tumors & 98 & $\mathrm{IHC}$ & Metastasis and overall survival & $(16)$ \\
\hline & Tumors & 58 & $\mathrm{IHC}$ & Metastasis, TNM stage and tumor formation & (97) \\
\hline & Tumors & 190 & $\mathrm{IHC}$ & $\begin{array}{l}\text { Lymphangiogenesis, lymphatic invasion, } \\
\text { recurrence and overall survival }\end{array}$ & $(17)$ \\
\hline & Plasma & 76 & RT-qPCR & Overall survival & $(18)$ \\
\hline & Tumors & 88 & $\mathrm{IHC}$ & Overall survival & $(110)$ \\
\hline & Tumors & 7 & $\mathrm{IHC}$ & EMT & $(91)$ \\
\hline \multirow[t]{2}{*}{ NSCLC } & Tumors & 180 & $\mathrm{IHC}$ & $\begin{array}{l}\text { Differentiation, TNM stage, lymph node metastasis, } \\
\text { disease-free survival and overall survival }\end{array}$ & $(23)$ \\
\hline & Plasma & 272 & RT-qPCR & $\begin{array}{l}\text { NSCLC stage, lymph node metastasis, disease-free survival } \\
\text { and overall survival }\end{array}$ & (24) \\
\hline \multirow[t]{3}{*}{ Breast cancer } & Tumors & 164 & SNP & Chemotherapy, event-free survival and overall survival & $(26)$ \\
\hline & Tumors & 300 & $\begin{array}{l}\text { RT-qPCR } \\
\text { and IHC }\end{array}$ & $\begin{array}{l}\text { Relapse-free survival, breast cancer-specific survival and } \\
\text { mortality }\end{array}$ & (129) \\
\hline & Tumors & 198 & $\mathrm{IHC}$ & Relapse-free survival, disease-free survival and overall survival & $(27)$ \\
\hline \multirow[t]{5}{*}{$\mathrm{HCC}$} & Tumors & 187 & SNP & Recurrence and overall survival & $(84)$ \\
\hline & Tumors & 160 & RT-qPCR & Recurrence and overall survival & $(34)$ \\
\hline & Tumors & 60 & $\mathrm{IHC}$ & Edmondson classification, TNM stage and overall survival & $(35)$ \\
\hline & Tumors & 50 & $\mathrm{IHC}$ & Edmondson classification, TNM stage and overall survival & $(38)$ \\
\hline & Tumors & 80 & $\mathrm{IHC}$ & $\begin{array}{l}\text { Tumor formation, Edmondson classification, TNM stage and } \\
\text { overall survival }\end{array}$ & $(36)$ \\
\hline \multirow[t]{2}{*}{ Ovarian cancer } & Tumors & 52 & $\begin{array}{l}\text { RT-qPCR } \\
\text { and WB }\end{array}$ & Clinical stage and overall survival & $(40)$ \\
\hline & $\begin{array}{l}\text { Tumors } \\
\text { Serum }\end{array}$ & 92 & IHC ELISA & Lymph node metastasis FIGO stage and lymph node metastasis & $(41)$ \\
\hline \multirow[t]{2}{*}{ Renal cancer } & Tumors & 73 & $\mathrm{IHC}$ & TNM stage, overall survival and disease-free survival & $(42)$ \\
\hline & Tumors & 112 & $\mathrm{IHC}$ & TNM stage, metastasis and disease-free survival & $(43)$ \\
\hline \multirow[t]{2}{*}{ Glioma } & Tumors & 107 & $\begin{array}{l}\text { RT-qPCR } \\
\text { and IHC }\end{array}$ & Pathological grade and overall survival & $(44)$ \\
\hline & Tumors & 52 & $\begin{array}{l}\text { RT-qPCR } \\
\text { and IHC }\end{array}$ & WHO grade, overall survival & $(45)$ \\
\hline \multirow[t]{2}{*}{ GBC } & Tumors & 40 & $\mathrm{IHC}$ & Lymph node metastasis, perineural invasion and overall survival & $(46)$ \\
\hline & Tumors & 70 & $\mathrm{IHC}$ & $\begin{array}{l}\text { Lymph node metastasis, TNM stage, perineural invasion } \\
\text { and overall survival }\end{array}$ & (47) \\
\hline TSCC & Tumors & 60 & $\mathrm{IHC}$ & Lymphatic metastasis, overall survival and cisplatin resistance & $(48)$ \\
\hline OS & Tumors & 116 & $\mathrm{IHC}$ & Clinical stage, distant metastasis and overall survival & $(49)$ \\
\hline Esophageal cancer & Tumors & 60 & $\mathrm{IHC}$ and $\mathrm{WB}$ & TNM stage and pathology grade & $(52)$ \\
\hline Pancreatic cancer & Serum & 60 & ELISA & Lymph node metastasis, distant metastasis and TNM stage & $(54)$ \\
\hline Klatskin tumors & Tumors & 76 & $\mathrm{IHC}$ & Tumor recurrence, overall survival and disease-free survival & $(55)$ \\
\hline SACC & Tumors & 65 & $\mathrm{IHC}$ & Tumor histological grading and invasion & $(56)$ \\
\hline Cervical cancer & Tumors & 104 & $\mathrm{IHC}$ & Overall survival, FIGO stage and lymph nodes metastasis & (57) \\
\hline
\end{tabular}

an applicable, sensitive and specific biomarker in CRC (87). Therefore, the present review suggests that studies focusing on whether MACC1 SNPs in plasma are associated with overall survival of patients with CRC patients are required. Additional 
Table II. Correlation of metastasis-associated in colon cancer 1 to clinical parameters in colorectal cancer (in studies published from 2013 onwards).

\begin{tabular}{|c|c|c|c|c|c|}
\hline Sample type & $\mathrm{n}$ & Method & Correlation to clinical parameters & Country involved & (Refs.) \\
\hline Tumors & 93 & $\mathrm{IHC}$ & Cancer initiation, invasion and distant metastasis & Rochester, USA & (63) \\
\hline Tumors & 51 & $\mathrm{IHC}$ & Conventional colitis-associated colorectal cancer tumorigenesis & New York, USA & (64) \\
\hline Tumors & 174 & RT-qPCR & $\begin{array}{l}\text { Tumor invasion, distant metastasis, disease-free survival } \\
\text { and overall survival }\end{array}$ & Osaka, Japan & (65) \\
\hline Tumors & 99 & RT-qPCR & Metastasis-free survival & Berlin, Germany & (66) \\
\hline Tumors & 187 & $\mathrm{IHC}$ & $\begin{array}{l}\text { TNM stage, invasion, prediction of metastasis and allover } \\
\text { survival }\end{array}$ & Bern, Switzerland & (67) \\
\hline Tumors & 323 & $\mathrm{IHC}$ & $\begin{array}{l}\text { Histological differentiation, UICC stage, TNM stage and } \\
\text { overall survival }\end{array}$ & Guangzhou, China & (68) \\
\hline Tumors & 96 & $\mathrm{IHC}$ & Lymph node metastasis, $\mathrm{T}$ stage and metastasis-free survival & Jinan, China & (70) \\
\hline
\end{tabular}

TNM, tumor-node-metastasis; UICC, Union for International Cancer Control; RT-qPCR, reverse transcription-quantitative polymerase chain reaction; IHC, immunohistochemistry.

studies with large sample sizes are required to reveal the potential association between MACC1 SNPs and stage classification, recurrence or prognosis.

\section{Potential mechanisms of cell proliferation, invasion and migration induced by MACC1 in CRC cell cultures}

Upstream regulation of MACC1. MicroRNAs (miRNAs/miRs) have been revealed to serve an important role in promoting or suppressing tumor invasion and metastasis via regulating metastasis-associated genes $(88,89)$. Using in silico prediction and western blot assays, a negative correlation was identified between miR-143 and MACC1 in CRC. Through 3' untranslated region luciferase reporter gene analysis, it was revealed that miR-143 directly targeted MACC1 (90). In addition, miR-338-3p and miR-200a were also revealed to transcriptionally regulate $\mathrm{MACC} 1$ in gastric cancer and hepatocellular carcinoma, respectively $(91,92)$. According to several studies (93-96), miR-338-3p and miR-200a are associated with invasion, migration, EMT and prognosis in patients with CRC. We hypothesize that they may negatively regulate $\mathrm{MACC} 1$ in CRC.

Stein et al (6) revealed that the inhibition of mitogen-activated protein kinase kinase reduced the level of MACC1 mRNA expression in the SW620 cell line, indicating that MACC 1 may be regulated by the 5 ' adenosine monophosphate-activated protein kinase (AMPK) signal pathway. This was also revealed in a gastric cancer cell in the study by Lin et al (97), whereby MACC1 overexpression via the AMPK signal pathway was revealed to promote the Warburg effect by upregulating the activities and expression of a series of glycolytic enzymes in gastric cancer. These results suggest that MACC1 is a metabolic stress-responsive gene that appears to serve an important role in tumor cell resistance against stress and escaping from stress by initiating metastasis. The majority of tumors, including colon tumors, are subjected to hypoxic conditions due to the abnormal vasculature that supplies them with oxygen and nutrients. However, the deficiency of oxygen causes hypoxia-inducible factor (HIF)-1 $\alpha$ stabilization.
Several studies confirmed that HIF-1 $\alpha$ stabilization induced metastasis via the hepatocyte growth factor (HGF)/Met signal pathway in solid types of cancer, including CRC (98-103). In addition, nutrient or environmental stress indicated by AMPK, a highly conserved sensor of cellular energy status found in all eukaryotic cells during hypoxia (104). Based on the aforementioned information, it is possible that MACC1 may be a stress responsive gene during hypoxic stress, which may be regulated by HIF-1 $\alpha$ stabilization in CRC. To overcome hypoxia and other metabolic stress, miR-511a and miR-483 were suppressed in metastatic colorectal cells and inhibited early metastatic colonization (105). Thus, the present study proposes that there may be an association between the two miRNAs and MACC1.

Recently, it was revealed that the cell-free DNA of tumors acts as a prometastatic factor through the induction of MACC1 via the Toll-like receptor 9 (TLR9) signaling pathway (106). TRL families serve a fundamental role in the activation of innate immunity. In particular, TLR9 signaling affects colorectal carcinogenesis and colonic inflammation (107). Notably, MACC1 is significantly associated with conventional colitis-associated colorectal cancer (CAC) tumorigenesis (64). Thus, it is hypothesized that the activation of the TRL9 signaling pathway by the cell-free DNA of tumors may respond to the stepwise upregulation of MACC1 expression from inflammatory bowel disease-associated colitis to dysplasia to adenocarcinoma.

The MACC1 promoter region from -426 to -18 was identified to be the essential domain, containing the functional binding sites for the transcription factors activator protein 1 (AP-1), specificity protein 1 (Sp1) and CCAAT-enhancer-binding protein (C/EBP). Using an electrophoretic mobility shift assay (EMSA) and a chromatin immunoprecipitation (ChIP) assay, it was additionally demonstrated that these transcription factors bound to the minimal essential MACC1 core promoter regions and regulated the transcription of the gene. In CRC tumors, the expression levels of c-Jun and Sp1 were significantly correlated with MACC1 expression levels $(\mathrm{P}=0.0007$ and $\mathrm{P}=0.02$, respectively) and the development of metachronous metastases 


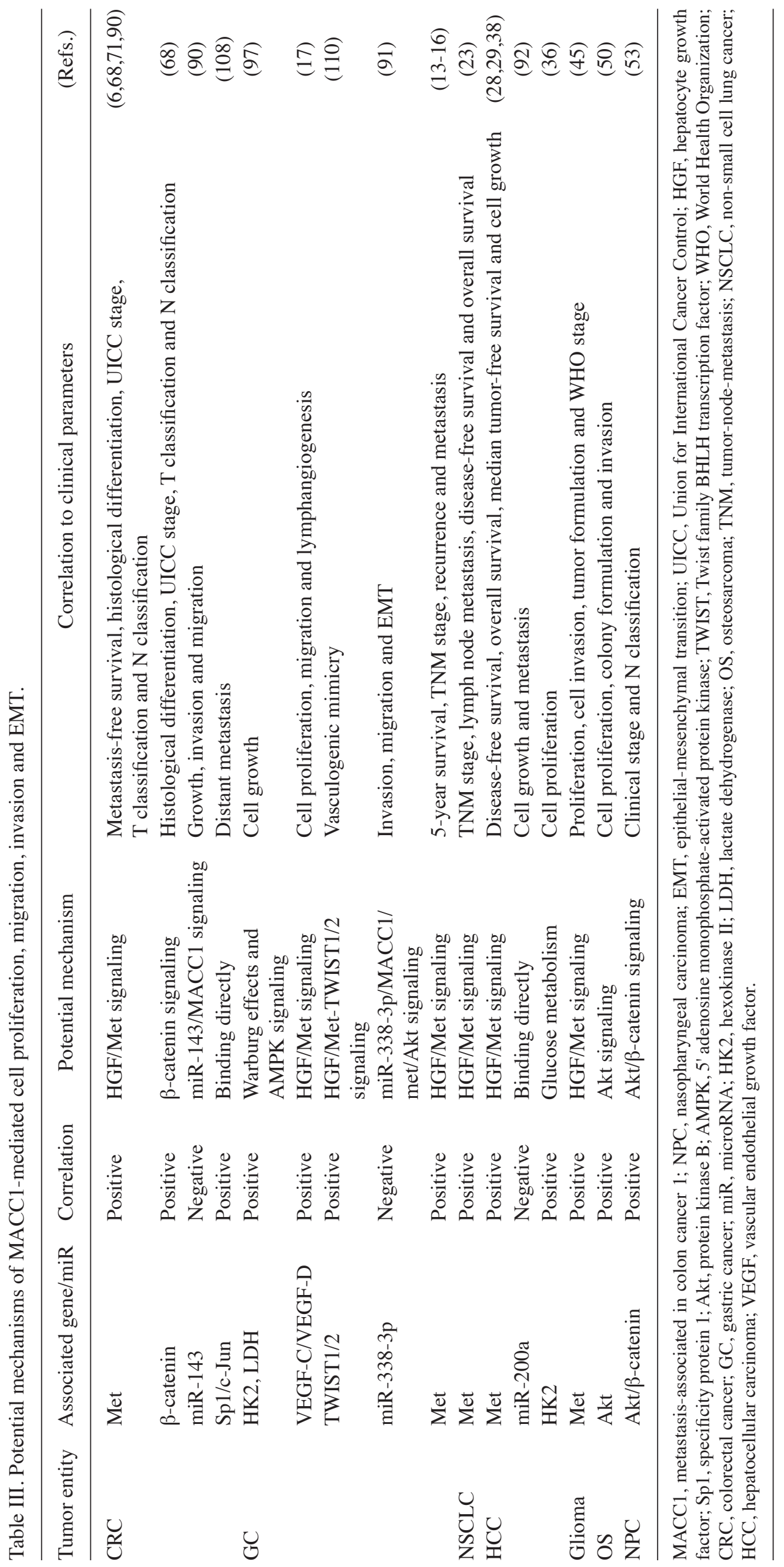




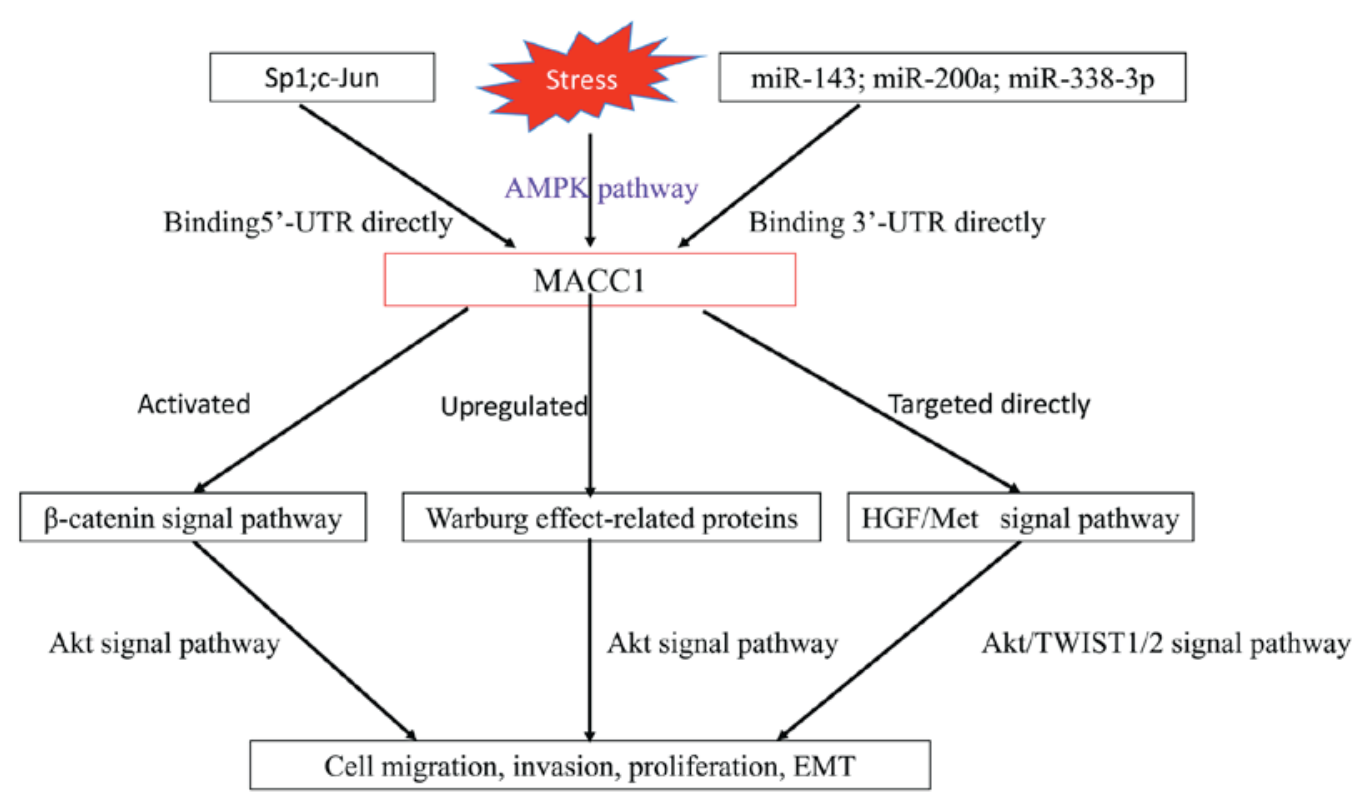

Figure 1. Potential mechanisms by which MACC1 induces cell proliferation, invasion, migration and EMT in CRC cell cultures. MACC1, metastasis-associated in colon cancer 1; EMT, epithelial-mesenchymal transition; Sp1, specificity protein 1; miR, microRNA; 3'-UTR, 3' untranslated region; AMPK, 5' adenosine monophosphate-activated protein kinase; HGF, hepatocyte growth factor; Akt, protein kinase B; TWIST, Twist family BHLH transcription factor.

$(\mathrm{P}=0.01$ and $\mathrm{P}=0.001$, respectively). At present, the upstream regulation of $\mathrm{MACC} 1$ in $\mathrm{CRC}$ remains unclear and requires additional investigation.

Downstream regulation of MACC1. Stein et al (6) identified a strong correlation between the levels of MACC1 and Met mRNA in stage I, II and III tumors $(\mathrm{P}=0.022)$. To investigate the association between MACC1 and the expression of Met, the authors analyzed the Met mRNA and protein levels in the human colon carcinoma SW480 and SW620 cell lines, which have low and high expression levels of MACC1, respectively. Though the transfection of a MACC1 overexpression vector, it was revealed that the mRNA and protein levels of Met were upregulated in the SW480 cell line. Conversely, Met was strongly downregulated subsequent to transfecting MACC1-specific small interfering RNA into the SW620 cell line. Finally, an additional study demonstrated that MACC1 combined with the promoter of the Met gene, as determined using ChIP and EMSA (109). These data suggested that the Met gene was a transcriptional target of MACC1. Subsequently, the correlation between MACC1 and Met expression was verified in CRC $(6,68,69,71,90)$ and other cancer tissues $(15-17,22,38$, $39,41,45,53,91,95,110)$. It was revealed that MACC1 promoted tumor growth and metastasis through the HGF/Met signal pathway. However, by examining 52 matched pairs of CRC and tumorous surrounding tissues, it was found that MACC1 overexpression per se was not sufficient to cause the significant upregulation of Met. Notably, it was suggested that Met was significantly upregulated only when the overexpression of MACC1 was coupled with miR-1 downregulation (111).

Furthermore, Galimi et al (71) revealed that MACC1 expression may contribute to CRC progression through additional mechanisms such as $\beta$-catenin signaling. MACC1 expression and $\beta$-catenin abnormal expression $(\mathrm{P}=0.033)$ were also identified in NPC. A previous study demonstrated that MACC1 served an important role in the carcinogenesis of NPC through the protein kinase $\mathrm{B} / \beta$-catenin signaling pathway (53). In support of this, Zhen et al (68) additionally revealed that MACC1 overexpression increased the expression of $\beta$-catenin, the downstream genes of MACC1, including c-Myc, cyclin D1, and MMP9, and the upstream gene of MACC1, phospho-glycogen synthase kinase $3 \beta$.

MACC1 was revealed to be was significantly associated with cisplatin resistance. The downregulation of MACC1 reduced the level of cisplatin resistance and induced apoptosis in tongue squamous cell carcinoma and human glioblastoma U251 cells $(48,112)$. Stein et al (109) revealed that MACC1 functioned via binding to a special consensus sequence of Met promoter, described as a Sp1 binding site. The ATP-binding cassette sub-family $\mathrm{G}$ member 2 (ABCG2) promoter region exhibited the same consensus sequence and the inhibition of Sp1-dependent ABCG2 expression caused chemosensitization to cisplatin (113). Therefore, it is possible that ABCG2 may be a transcriptional target of $\mathrm{MACC} 1$, and cisplatin resistance may be caused by the increase of ABCG2 induced by the overexpression of MACC1. Recently, multiple studies showed that the activation of the $\mathrm{Wnt} / \beta$-catenin pathway enhanced cisplatin resistance, whereas Wnt/ $\beta$-catenin pathway inhibition sensitized cancer cells to cisplatin (114-118). Overall, the $\mathrm{Wnt} / \beta$-catenin pathway serves a critical role in cisplatin resistance and MACC1 overexpression may enhance cisplatin resistance via activing the $\mathrm{Wnt} / \beta$-catenin pathway.

MACC1 has been demonstrated to promote vasculogenic mimicry (VM) by upregulating Twist family BHLH transcription factor (TWIST) $1 / 2$ through the $\mathrm{HGF} / \mathrm{Met}$ signal pathway in gastric cancer (110). TWIST1/2 were revealed to be associated with EMT and were also valuable biomarkers in CRC $(119,120)$. Thus, it was hypothesized that MACC1 induced EMT via the HGF/MET/TWIST1/2 signal pathway in CRC.

Despite advances with regard to our understanding of the association between MACC1 expression and the survival 
of patients with $\mathrm{CRC}$, little is known about the mechanisms behind the induction of cell proliferation, invasion and migration by $\mathrm{MACC} 1$ in $\mathrm{CRC}$ cell cultures. It is therefore necessary to identify these complex internal mechanisms.

\section{Conclusions}

In CRC, metastasis is the most frequent cause of treatment failure and it is responsible for $90 \%$ of patient mortality. However, there is no molecular biomarker sufficient for predicting the risk of tumor progression and metastasis. Numerous studies have revealed that MACC1 expression and SNPs are correlated with metastasis-free survival. Therefore, MACC1 status may be regarded as a tumor stage-independent predictor for CRC metastasis.

Met, identified as a transcriptional target of MACC1, is associated with CRC metastasis (121-129). However, MACC1 induces colon cancer cell growth, invasion and migration not only by the $\mathrm{HGF} / \mathrm{Met}$ signal pathway, but also by the $\beta$-catenin signal pathway. Additionally, miRNA (miR-143) and several transcription factors (AP-1, Sp1, and C/EBP) have been revealed to be involved in the negative or positive regulation of MACC1. However, the specific mechanism behind the upstream regulation of MACC1 remains unclear.

Based on the clinical and experimental evidence of MACC1 in $\mathrm{CRC}$, it may be considered as a promising biomarker for the prediction of CRC metastasis and disease prognosis. Several studies have reported that the downregulation of MACC1 inhibits colorectal tumor progression and metastasis in CRC cells and xenografted mice $(6,90,130)$. MACC1 may also act as a therapeutic target in the treatment of CRC. Due to the significantly higher expression of MACC1 in CRC tissues compared with other organs, enteric-coated products targeting MACC1 may be a good treatment strategy. However, little was previously known with regard to how MACC1 functions in CRC. The specific mechanisms of MACC1 should be additionally investigated, and MACC1-based retrospective studies or interventional strategies should be developed in larger clinical trials of CRC.

\section{Acknowledgements}

The authors would like to thank Mr. Chao Fang, Mr. XiangGuang Meng and Mr. Wei-Hua Huang for their valuable suggestions for the present study. The present study was supported by the National Natural Scientific Foundation of China (grant nos. 81273595, 81202594 and 81001445) and the '863' Project (grant no. 2012AA02A518).

\section{References}

1. Siegel R, Ma J, Zou Z and Jemal A: Cancer statistics, 2014. CA Cancer J Clin 64: 9-29, 2014

2. Stein U and Schlag PM: Clinical, biological, and molecular aspects of metastasis in colorectal cancer. Recent Results Cancer Res 176: 61-80, 2007.

3. Deliu IC, Georgescu EF and Bezna MC: Analysis of prognostic factors in colorectal carcinoma. Rev Med Chir Soc Med Nat Iasi 118: 808-816, 2014.

4. Sethi $\mathrm{N}$ and Kang Y: Unravelling the complexity of metastasis-molecular understanding and targeted therapies. Nat Rev Cancer 11: 735-748, 2011.

5. Wanebo HJ, LeGolvan M, Paty PB, Saha S, Zuber M, D'Angelica MI and Kemeny NE: Meeting the biologic challenge of colorectal metastases. Clin Exp Metastasis 29: 821-839, 2012.
6. Stein U, Walther W, Arlt F, Schwabe H, Smith J, Fichtner I, Birchmeier W and Schlag PM: MACC1, a newly identified key regulator of HGF-MET signaling, predicts colon cancer metastasis. Nat Med 15: 59-67, 2009.

7. Stein U, Dahlmann M and Walther W: MACC1-more than metastasis? Facts and predictions about a novel gene. J Mol Med (Berl) 88: 11-18, 2010.

8. Kokoszyńska K, Kryński J, Rychlewski L and Wyrwicz LS: Unexpected domain composition of MACC1 links MET signaling and apoptosis. Acta Biochim Pol 56: 317-323, 2009.

9. Wang R, Wei Z, Jin H, Wu H, Yu C, Wen W, Chan LN, Wen Z and Zhang M: Autoinhibition of UNC5b revealed by the cytoplasmic domain structure of the receptor. Mol Cell 33: 692-703, 2009.

10. Ipsaro JJ, Huang L and Mondragon A: Structures of the spectrin-ankyrin interaction binding domains. Blood 113: 5385-5393, 2009.

11. Reed JC, Doctor KS and Godzik A: The domains of apoptosis: A genomics perspective. Sci STKE 2004: re9, 2004.

12. Shirahata A, Sakata M, Kitamura Y, Sakuraba K, Yokomizo K, Goto T, Mizukami H, Saito M, Ishibashi K, Kigawa G, et al: MACC 1 as a marker for peritoneal-disseminated gastric carcinoma. Anticancer Res 30: 3441-3444, 2010.

13. Ge SH, Wu XJ, Wang XH, Xing XF, Zhang LH, Zhu YB, Du H, Dong B, Hu Y and Ji JF: Over-expression of metastasis-associated in colon cancer-1 (MACC1) associates with better prognosis of gastric cancer patients. Chin J Cancer Res 23: 153-159, 2011.

14. Wang L, Wu Y, Lin L, Liu P, Huang H, Liao W, Zheng D, Zuo Q, Sun L, Huang N, et al: Metastasis-associated in colon cancer-1 upregulation predicts a poor prognosis of gastric cancer, and promotes tumor cell proliferation and invasion. Int J Cancer 133: 1419-1430, 2013.

15. Ma J, Ma J, Meng Q, Zhao ZS and Xu WJ: Prognostic value and clinical pathology of MACC-1 and c-MET expression in gastric carcinoma. Pathol Oncol Res 19: 821-832, 2013.

16. Guo T, Yang J, Yao J, Zhang Y, Da M and Duan Y: Expression of MACC1 and c-Met in human gastric cancer and its clinical significance. Cancer Cell Int 13: 121, 2013.

17. Sun L, Duan J, Jiang Y, Wang L, Huang N, Lin L, Liao Y and Liao W: Metastasis-associated in colon cancer-1 upregulates vascular endothelial growth factor-C/D to promote lymphangiogenesis in human gastric cancer. Cancer Lett 357: 242-253, 2015.

18. Burock S, Herrmann P, Wendler I, Niederstrasser M, Wernecke KD and Stein U: Circulating metastasis associated in colon cancer 1 transcripts in gastric cancer patient plasma as diagnostic and prognostic biomarker. World J Gastroenterol 21: 333-341, 2015.

19. Shimokawa H, Uramoto H, Onitsuka T, et al: Macc1 amplification predicts postoperative recurrence in lung adenocarcinoma. Ann Oncol 21: 24-25, 2010.

20. Shimokawa H, Uramoto H, Onitsuka T, Chundong G, Hanagiri $T$, Oyama T and Yasumoto K: Overexpression of MACC1 mRNA in lung adenocarcinoma is associated with postoperative recurrence. J Thorac Cardiovasc Surg 141: 895-898, 2011.

21. Gu CD, Uramoto H, Onitsuka T, Shimokawa H, Iwanami T, Nakagawa M, Oyama T and Tanaka F: Molecular Diagnosis of MACC1 status in lung adenocarcinoma by immunohistochemical analysis. Anticancer Res 31: 1141-1145, 2011.

22. Hu X, Fu X, Wen S, Zou X and Liu Y: Prognostic value of MACC1 and c-met expressions in non-small cell lung cancer. Zhongguo Fei Ai Za Zhi 15: 399-403, 2012 (In Chinese).

23. Wang Z, Li Z, Wu C, Wang Y, Xia Y, Chen L, Zhu Q and Chen Y: MACC1 overexpression predicts a poor prognosis for non-small cell lung cancer. Med Oncol 31: 790, 2014.

24. Wang Z, Cai M, Weng Y, Zhang F, Meng D, Song J, Zhou H and Xie Z: Circulating MACC1 as a novel diagnostic and prognostic biomarker for nonsmall cell lung cancer. J Cancer Res Clin Oncol 141: 1353-1361, 2015.

25. Huang Y, Zhang H, Cai J, Fang L, Wu J, Ye C, Zhu X and Li M: Overexpression of MACC1 and its significance in human breast cancer progression. Cell Biosci 3: 16, 2013.

26. Muendlein A, Hubalek M, Geller-Rhomberg S, Gasser K, Winder T, Drexel H, Decker T, Mueller-Holzner E, Chamson M, Marth C and Lang AH: Significant survival impact of MACC1 polymorphisms in HER 2 positive breast cancer patients. Eur J Cancer 50: 2134-2141, 2014.

27. Kim GE, Lee JS, Park MH and Yoon JH: Metastasis associated in colon cancer 1 predicts poor outcomes in patients with breast cancer. Anal Quant Cytopathol Histpathol 37: 96-104, 2015.

28. Qiu J, Huang P, Liu Q, Hong J, Li B, Lu C, Wang L, Wang J and Yuan Y: Identification of MACC1 as a novel prognostic marker in hepatocellular carcinoma. J Transl Med 9: 166, 2011. 
29. Qu JH, Chang XJ, Lu YY, Bai WL, Chen Y, Zhou L, Zeng Z, Wang CP, An LJ, Hao LY, et al: Overexpression of metastasis-associated in colon cancer 1 predicts a poor outcome of hepatitis B virus-related hepatocellular carcinoma. World J Gastroenterol 18: 2995-3003, 2012.

30. Chang XJ, Wang CP, Qu JH, Lu YY, Chen Y, Bai WL, Gao XD, Hao LY, Xu GL, Wang H and Yang YP: Expression and clinical significance of metastasis-associated in colon cancer 1 (MACC1) in HBV-related hepatocellular carcinoma. Zhonghua Zhong Liu Za Zhi 34: 748-752, 2012

31. Yang YP, Qu JH, Chang XJ, Lu YY, Bai WL, Dong Z, Wang H, An LJ, Xu ZX, Wang CP, et al: High intratumoral metastasis-associated in colon cancer-1 expression predicts poor outcomes of cryoablation therapy for advanced hepatocellular carcinoma. J Transl Med 11: 41, 2013.

32. Xie C, Wu J, Yun J, Lai J, Yuan Y, Gao Z, Li M, Li J and Song L: MACC1 as a prognostic biomarker for early-stage and AFP-normal hepatocellular carcinoma. PLoS One 8: e64235, 2013.

33. Xie C, Li J, Xie DY, Wu JH, Li MF and Gao ZL: 761 Macc1 protein: A promising immunomarker for the detection of early stage and afp normal hepatocellular carcinomas. J Hepatol 56: S299, 2012

34. Gao S, Lin BY, Yang Z, Zheng ZY, Liu ZK, Wu LM, Xie HY, Zhou L and Zheng SS: Role of overexpression of MACC1 and/or FAK in predicting prognosis of hepatocellular carcinoma after liver transplantation. Int J Med Sci 11: 268-275, 2014

35. Ji D, Lu ZT, Li YQ, Liang ZY, Zhang PF, Li C, Zhang JL, Zheng X and Yao YM: MACC1 Expression correlates with PFKFB2 and survival in hepatocellular carcinoma. Asian Pac J Cancer P 15 999-1003, 2014.

36. Li Y, Lu Z, Liang Z, Ji D, Zhang P, Liu Q, Zheng X and Yao Y: Metastasis-associated in colon cancer-1 is associated with poor prognosis in hepatocellular carcinoma, partly by promoting proliferation through enhanced glucose metabolism. Mol Med Rep 12: 426-434, 2015.

37. Sun DW, Zhang YY, Qi Y, Liu GQ, Chen YG, Ma J and Lv GY: Prognostic and clinicopathological significance of MACC1 expression in hepatocellular carcinoma patients: A meta-analysis. Int J Clin Exp Med 8: 4769-4777, 2015.

38. Yao Y, Dou C, Lu Z, Zheng X and Liu Q: MACC1 suppresses cell apoptosis in hepatocellular carcinoma by targeting the HGF/c-MET/AKT pathway. Cell Physiol Biochem 35: 983-996, 2015.

39. Zhang RT, Shi HR, Huang HL, Chen ZM, Liu HN and Yuan ZF Expressions of MACC1, HGF and C-met protein in epithelial ovarian cancer and their significance. Nan Fang Yi Ke Da Xue Xue Bao 31: 1551-1555, 2011 (In Chinese).

40. Zhang RT, Ren F and Shi HR: Expression of metastasis-associated in colon cancer-1 in different stages of epithelial ovarian cancer. Zhongguo Yi Xue Ke Xue Yuan Xue Bao 36: 47-51, 2014 (In Chinese).

41. Li H, Zhang H, Zhao S, Shi Y, Yao J, Zhang Y, Guo H and Liu X: Overexpression of MACC1 and the association with hepatocyte growth factor/c-Met in epithelial ovarian cancer. Oncol Lett 9: 1989-1996, 2015

42. Hu H, Tian D, Chen T, Han R, Sun Y and Wu C: Metastasisassociated in colon cancer 1 is a novel survival-related biomarker for human patients with renal pelvis carcinoma. PLoS One 9: e100161, 2014

43. Jin Z, Xu N, Guo K, Xu P, Li P, Zhang Y, Li X, Zheng S, Liu C, $\mathrm{Xu} \mathrm{A}$ and Huang P: Increased expression of metastasis-associated in colon cancer-1 in renal cell carcinoma is associated with poor prognosis. Int J Clin Exp Pathol 8: 3857-3863, 2015.

44. Yang T, Kong B, Kuang YQ, Cheng L, Gu JW, Zhang JH, Shu HF, Yu SX, He WQ, Xing XM and Huang HD: Overexpression of MACC1 protein and its clinical implications in patients with glioma. Tumor Biol 35: 815-819, 2014

45. Hagemann C, Fuchs S, Monoranu CM, Herrmann P, Smith J, Hohmann T, Grabiec U, Kessler AF, Dehghani F, Löhr M, et al: Impact of MACC1 on human malignant glioma progression and patients unfavorable prognosis. Neuro Oncol 15: 1696-1709, 2013.

46. Wang Y, Hong Q, Wang J, Fang Y and Hu C: Downregulated expression of metastasis associated in colon cancer 1 (MACC1) reduces gallbladder cancer cell proliferation and invasion. Tumor Biol 35: 3771-3778, 2014.

47. Chen L, Wang J, Fu L, Zhang B, Zhang H and Ye B: Prognostic significance of metastasis associated in colon cancer 1 (MACC1) expression in patients with gallbladder cancer. J Cancer Res Ther 10: 1052-1056, 2014
48. Li HF, Liu YQ, Shen ZJ, Gan XF, Han JJ, Liu YY, Li HG1 and Huang ZQ: Downregulation of MACC1 inhibits invasion, migration and proliferation, attenuates cisplatin resistance and induces apoptosis in tongue squamous cell carcinoma. Oncol Rep 33: 651-660, 2015.

49. Zhang K, Zhang Y, Zhu H, Xue N, Liu J, Shan C and Zhu Q: High expression of MACC1 predicts poor prognosis in patients with osteosarcoma. Tumor Biol 35: 1343-1350, 2014.

50. Zhang K, Tian F, Zhang Y, Zhu Q, Xue N, Zhu H, Wang H and Guo X: MACC1 is involved in the regulation of proliferation, colony formation, invasion ability, cell cycle distribution, apoptosis and tumorigenicity by altering Akt signaling pathway in human osteosarcoma. Tumor Biol 35: 2537-2548, 2014.

51. Zhu M, Xu Y, Mao X, Gao Y, Shao L and Yan F: Overexpression of metastasis-associated in colon cancer-1 associated with poor prognosis in patients with esophageal cancer. Pathol Oncol Res 19: 749-753, 2013.

52. Wang JJ, Hong Q, Hu CG, Fang YJ and Wang Y: Significance of MACC1 protein expression in esophageal carcinoma. Zhonghua yi xue za zhi 93: 2584-2586, 2013 (In Chinese)

53. Meng FJ, Li H, Shi H, Yang Q, Zhang F, Yang Y, Kang L, Zhen T, Dong DY and Han A: MACC1 down-regulation inhibits proliferation and tumourigenicity of nasopharyngeal carcinoma cells through Akt/ $\beta$-catenin signaling pathway. PLoS One 8: e60821, 2013.

54. Wang G, Kang MX, Lu WJ, Chen Y, Zhang B and Wu YL: MACC1: A potential molecule associated with pancreatic cancer metastasis and chemoresistance. Oncol Lett 4: 783-791, 2012.

55. Lederer A, Herrmann P, Seehofer D, Dietel M, Pratschke J, Schlag P and Stein U: Metastasis-associated in colon cancer 1 is an independent prognostic biomarker for survival in klatskin tumor patients. Hepatology 62: 841-850, 2015.

56. Li H, Liao X, Liu Y, Shen Z, Gan X, Li H and Huang Z: The expression of MACC1 and its role in the proliferation and apoptosis of salivary adenoid cystic carcinoma. J Oral Pathol Med 44: 810-817, 2015.

57. Guo L,Lu W,Zhang X, Luo D and Zhang H: Metastasis-associated colon cancer-1 is a novel prognostic marker for cervical cancer. Int J Clin Exp Pathol 7: 4150-4155, 2014.

58. Shirahata A, Shinmura K, Kitamura Y, Sakuraba K, Yokomizo K, Goto T, Mizukami H, Saito M, Ishibashi K, Kigawa G, et al: MACC1 as a marker for advanced colorectal carcinoma. Anticancer Res 30: 2689-2692, 2010.

59. Lang AH, Geller-Rhomberg S, Winder T, Stark N, Gasser K, Hartmann B, Kohler B, Grizelj I, Drexel H and Muendlein A: A common variant of the MACC1 gene is significantly associated with overall survival in colorectal cancer patients. BMC Cancer 12: 20, 2012.

60. Schmid F, Burock S, Klockmeier K, Schlag PM and Stein U: SNPs in the coding region of the metastasis-inducing gene MACC1 and clinical outcome in colorectal cancer. Mol Cancer 11: 49, 2012.

61. Stein U, Burock S, Herrmann P, Wendler I, Niederstrasser M, Wernecke KD and Schlag PM: Circulating MACC1 transcripts in colorectal cancer patient plasma predict metastasis and prognosis. PLos One 7: e49249, 2012

62. Isella C,Mellano A, Galimi F,Petti C, Capussotti L, De Simone M, Bertotti A, Medico E and Muratore A: MACC1 mRNA levels predict cancer recurrence after resection of colorectal cancer liver metastases. Ann Surg 257: 1089-1095, 2013.

63. Ren B, Zakharov V, Yang Q, McMahon L, Yu J and Cao W: $\mathrm{MACC} 1$ is related to colorectal cancer initiation and early-stage invasive growth. Am J Clin Pathol 140: 701-707, 2013.

64. Harpaz N, Taboada S, Ko HM, Yu J, Yang Q, Xu H and Cao W: Expression of MACC1 and MET in inflammatory bowel disease-associated colonic neoplasia. Inflamm Bowel Dis 20: 703-711, 2014.

65. Yamamoto H, Miyoshi N, Mimori K, Hitora T, Tokuoka M, Fujino S, Ellis HL, Ishii H, Noura S, Ohue M, et al: MACC1 expression levels as a novel prognostic marker for colorectal cancer. Oncol Lett 8: 2305-2309, 2014.

66. Ilm K, Kemmner W, Osterland M, Burock S, Koch G, Herrmann P, Schlag PM and Stein U: High MACC1 expression in combination with mutated KRAS G13 indicates poor survival of colorectal cancer patients. Mol Cancer 14: 38, 2015.

67. Koelzer VH, Herrmann P, Zlobec I, Karamitopoulou E, Lugli A and Stein U: Heterogeneity analysis of metastasis associated in colon cancer 1 (MACC1) for survival prognosis of colorectal cancer patients: A retrospective cohort study. BMC Cancer 15: $160,2015$. 
68. Zhen T, Dai S, Li H, Yang Y, Kang L, Shi H, Zhang F, Yang D, Cai S, He Y, et al: MACC1 promotes carcinogenesis of colorectal cancer via $\beta$-catenin signaling pathway. Oncotarget 5: 3756-3769, 2014.

69. Kawamura M, Saigusa S, Toiyama Y, Tanaka K, Okugawa Y, Hiro J, Uchida K, Mohri Y, Inoue Y and Kusunoki M: Correlation of MACC1 and MET expression in rectal cancer after neoadjuvant chemoradiotherapy. Anticancer Res 32: 1527-1531, 2012.

70. Ge Y, Meng X, Zhou Y, Zhang J and Ding Y: Positive MACC1 expression correlates with invasive behaviors and postoperative liver metastasis in colon cancer. Int J Clin Exp Med 8: 1094-1100, 2015.

71. Galimi F, Torti D, Sassi F, Isella C, Corà D, Gastaldi S, Ribero D, Muratore A, Massucco P, Siatis D, et al: Genetic and expression analysis of MET, MACC1, and HGF in metastatic colorectal cancer: Response to met inhibition in patient xenografts and pathologic correlations. Clin Cancer Res 17: 3146-3156, 2011.

72. Boardman LA: Overexpression of MACC1 leads to downstream activation of HGF/MET and potentiates metastasis and recurrence of colorectal cancer. Genome Med 1: 36, 2009.

73. Nitsche U, Rosenberg R, Balmert A, Schuster T, SlottaHuspenina J, Herrmann P, Bader FG, Friess H, Schlag PM, Stein U and Janssen KP: Integrative marker analysis allows risk assessment for metastasis in stage II colon cancer. Ann Surg 256: 763-771, 2012.

74. Stroun M, Anker P, Maurice P, Lyautey J, Lederrey C and Beljanski M: Neoplastic characteristics of the DNA found in the plasma of cancer patients. Oncology 46: 318-322, 1989.

75. Kopreski MS, Benko FA, Kwak LW and Gocke CD: Detection of tumor messenger RNA in the serum of patients with malignant melanoma. Clin Cancer Res 5: 1961-1965, 1999.

76. Silva JM, Dominguez G, Silva J, Garcia JM, Sanchez A, Rodriguez O, Provencio M, España P and Bonilla F: Detection of epithelial messenger RNA in the plasma of breast cancer patients is associated with poor prognosis tumor characteristics. Clin Cancer Res 7: 2821-2825, 2001.

77. Silva JM, Rodriguez R, Garcia JM, Muñoz C, Silva J, Dominguez G, Provencio M, España P and Bonilla F: Detection of epithelial tumour RNA in the plasma of colon cancer patients is associated with advanced stages and circulating tumour cells. Gut 50: 530-534, 2002

78. Garcia V, Garcia JM, Silva J, Martin P, Peña C, Dominguez G, Diaz R, Herrera M, Maximiano C, Sabin P, et al: Extracellular tumor-related mRNA in plasma of lymphoma patients and survival implications. PLoS One 4: e8173, 2009.

79. Stein U, Burock S, Herrmann P, Wendler I, Niederstrasser M, Wernecke KD and Schlag PM: Diagnostic and prognostic value of metastasis inducer S100A4 transcripts in plasma of colon, rectal, and gastric cancer patients. J Mol Diagn 13: 189-198, 2011

80. Mohammed N, Rodriguez M, Garcia V, Garcia JM, Dominguez G, Peña C, Herrera M, Gomez I, Diaz R, Soldevilla B, et al: EPAS1 mRNA in plasma from colorectal cancer patients is associated with poor outcome in advanced stages. Oncol Lett 2: 719-724, 2011.

81. Shen J, Wei J, Guan W, Wang H, Ding Y, Qian X, Yu L, Zou Z, Xie L, Costa C, et al: Plasma mRNA expression levels of BRCA1 and TS as potential predictive biomarkers for chemotherapy in gastric cancer. J Transl Med 12: 355, 2014

82. Kishikawa T, Otsuka M, Ohno M, Yoshikawa T, Takata A and Koike K: Circulating RNAs as new biomarkers for detecting pancreatic cancer. World J Gastroenterol 21: 8527-8540, 2015.

83. García JM, García V, Peña C, Domínguez G, Silva J, Diaz R, Espinosa P, Citores MJ, Collado M and Bonilla F: Extracellular plasma RNA from colon cancer patients is confined in a vesicle-like structure and is mRNA-enriched. RNA 14: 1424-1432, 2008.

84.Zheng Z, Gao S, Yang Z, Xie H, Zhang C, Lin B, Wu L, Zheng S and Zhou L: Single nucleotide polymorphisms in the metastasis-associated in colon cancer-1 gene predict the recurrence of hepatocellular carcinoma after transplantation. Int J Med Sci 11: 142-150, 2014

85. Siravegna G, Mussolin B, Buscarino M, Corti G, Cassingena A, Crisafulli G, Ponzetti A, Cremolini C, Amatu A, Lauricella C, et al: Clonal evolution and resistance to EGFR blockade in the blood of colorectal cancer patients. Nat Med 21: 795-801, 2015.

86. Mouliere F, Robert B, Arnau Peyrotte E, Del Rio M, Ychou M, Molina F, Gongora C and Thierry AR: High fragmentation characterizes tumour-derived circulating DNA. PLoS One 6: e23418, 2011.
87. Bettegowda C, Sausen M, Leary RJ, Kinde I, Wang Y, Agrawal N, Bartlett BR, Wang H, Luber B, Alani RM, et al: Detection of circulating tumor DNA in early- and late-stage human malignancies. Sci Transl Med 6: 224ra224, 2014.

88. Hwang HW and Mendell JT: MicroRNAs in cell proliferation, cell death, and tumorigenesis. Br J Cancer 96 (Suppl): R40-R44, 2007.

89. Calin GA and Croce CM: MicroRNA signatures in human cancers. Nat Rev Cancer 6: 857-866, 2006.

90. Zhang Y, Wang ZQ, Chen M, Peng L, Wang X, Ma Q, Ma F and Jiang B: MicroRNA-143 targets MACC1 to inhibit cell invasion and migration in colorectal cancer. Mol Cancer 11: 23, 2012.

91. Huang N, Wu Z, Lin L, Zhou M, Wang L, Ma H, Xia J, Bin J, Liao Y and Liao W: MiR-338-3p inhibits epithelial-mesenchymal transition in gastric cancer cells by targeting ZEB2 and MACC1/Met/Akt signaling. Oncotarget 6: 15222-15234, 2015.

92. Feng J, Wang J, Chen M, Chen G, Wu Z, Ying L, Zhuo Q, Zhang J and Wang W: miR-200a suppresses cell growth and migration by targeting MACC1 and predicts prognosis in hepatocellular carcinoma. Oncol Rep 33: 713-720, 2015.

93. Xue Q, Sun K, Deng HJ, Lei ST, Dong JQ and Li GX: MicroRNA-338-3p inhibits colorectal carcinoma cell invasion and migration by targeting smoothened. Jpn J Clin Oncol 44: $13-21,2014$.

94. Sun K, Su G, Deng H, Dong J, Lei S and Li G: Relationship between miRNA-338-3p expression and progression and prognosis of human colorectal carcinoma. Chin Med J (Engl) 127: 1884-1890, 2014.

95. Sheng XJ, Li Z, Sun M, Wang ZH, Zhou DM, Li JQ, Zhao Q, Sun XF and Liu QC: MACC1 induces metastasis in ovarian carcinoma by upregulating hepatocyte growth factor receptor c-MET. Oncol Lett 8: 891-897, 2014.

96. Pichler M, Ress AL, Winter E, Stiegelbauer V, Karbiener M, Schwarzenbacher D, Scheideler M, Ivan C, Jahn SW, Kiesslich T, et al: MiR-200a regulates epithelial to mesenchymal transition-related gene expression and determines prognosis in colorectal cancer patients. Br J Cancer 110: 1614-1621, 2014.

97. Lin L, Huang H, Liao W, Ma H, Liu J, Wang L, Huang N, Liao Y and Liao W: MACC1 supports human gastric cancer growth under metabolic stress by enhancing the Warburg effect. Oncogene 34: 2700-2710, 2015.

98. Hara S, Nakashiro K, Klosek SK, Ishikawa T, Shintani S and Hamakawa H: Hypoxia enhances c-Met/HGF receptor expression and signaling by activating HIF-lalpha in human salivary gland cancer cells. Oral Oncol 42: 593-598, 2006.

99. Chen HH, Su WC, Lin PW, Guo HR and Lee WY: Hypoxiainducible factor-1alpha correlates with MET and metastasis in node-negative breast cancer. Breast Cancer Res Treat 103: $167-175,2007$.

100. Comito G, Calvani M, Giannoni E, Bianchini F, Calorini L, Torre E, Migliore C, Giordano S and Chiarugi P: HIF-1 $\alpha$ stabilization by mitochondrial ROS promotes Met-dependent invasive growth and vasculogenic mimicry in melanoma cells. Free Radic Biol Med 51: 893-904, 2011.

101. Ide T, Kitajima Y, Miyoshi A, Ohtsuka T, Mitsuno M, Ohtaka K and Miyazaki K: The hypoxic environment in tumor-stromal cells accelerates pancreatic cancer progression via the activation of paracrine hepatocyte growth factor/c-Met signaling. Ann Surg Oncol 14: 2600-2607, 2007.

102. Kim BW, Cho H, Chung JY, Conway C, Ylaya K, Kim JH and Hewitt SM: Prognostic assessment of hypoxia and metabolic markers in cervical cancer using automated digital image analysis of immunohistochemistry. J Transl Med 11: 185, 2013.

103. Chen Z, He X, Xia W, Huang Q, Zhang Z, Ye J, Ni C, Wu P, Wu D, $\mathrm{Xu} \mathrm{J}$, et al: Prognostic value and clinicopathological differences of HIFs in colorectal cancer: Evidence from meta-analysis. PLoS One 8: e80337, 2013.

104. Hardie DG: The AMP-activated protein kinase pathway-new players upstream and downstream. J Cell Sci 117: 5479-5487, 2004.

105. Loo JM, Scherl A, Nguyen A, Man FY, Weinberg E, Zeng Z, Saltz L, Paty PB and Tavazoie SF: Extracellular metabolic energetics can promote cancer progression. Cell 160: 393-406, 2015.

106. Fúri I, Kalmár A, Wichmann B, Spisák S, Schöller A, Barták B, Tulassay Z and Molnár B: Cell free DNA of tumor origin induces a 'metastatic' expression profile in HT-29 cancer cell line. PLoS One 10: e0131699, 2015.

107. Fúri I, Sipos F, Germann TM, Kalmár A, Tulassay Z, Molnár B and Múzes G: Epithelial toll-like receptor 9 signaling in colorectal inflammation and cancer: Clinico-pathogenic aspects. World J Gastroenterol 19: 4119-4126, 2013. 
108. Juneja M, Ilm K, Schlag PM and Stein U: Promoter identification and transcriptional regulation of the metastasis gene MACC1 in colorectal cancer. Mol Oncol 7: 929-943, 2013.

109. Stein U, Smith J, Walther W and Arlt F: MACC1 controls Met: What a difference an Sp1 site makes. Cell Cycle 8: 2467-2469, 2009.

110. Wang L, Lin L, Chen X, Sun L, Liao Y, Huang N and Liao W: Metastasis-associated in colon cancer-1 promotes vasculogenic mimicry in gastric cancer by upregulating TWIST1/2. Oncotarget 6: 11492-11506, 2015.

111. Migliore C, Martin V, Leoni VP, Restivo A, Atzori L, Petrelli A, Isella C,Zorcolo L, Sarotto I, Casula G, et al: MiR-1 downregulation cooperates with MACC1 in promoting MET overexpression in human colon cancer. Clin Cancer Res 18: 737-747, 2012.

112. Shang C, Hong Y, Guo Y, Liu YH and Xue YX: Influence of the MACC1 gene on sensitivity to chemotherapy in human U251 glioblastoma cells. Asian Pac J Cancer Prev 16: 195-199, 2015.

113. Yang WJ, Song MJ, Park EY, Lee JJ, Park JH, Park K, Park JH and Kim HP: Transcription factors Sp1 and Sp3 regulate expression of human ABCG2 gene and chemoresistance phenotype. Mol Cells 36: 368-375, 2013.

114. Gao Y, Liu Z, Zhang X, He J, Pan Y, Hao F, Xie L, Li Q, Qiu X and Wang E: Inhibition of cytoplasmic GSK-3 $\beta$ increases cisplatin resistance through activation of $\mathrm{Wnt} / \beta$-catenin signaling in A549/DDP cells. Cancer Lett 336: 231-239, 2013.

115. Wei Y, Shen N, Wang Z, Yang G, Yi B, Yang N, Qiu Y and $\mathrm{Lu}$ J: Sorafenib sensitizes hepatocellular carcinoma cell to cisplatin via suppression of Wnt/ $\beta$-catenin signaling. Mol Cell Biochem 381: 139-144, 2013.

116. Zhao H, Wei W, Sun Y, Gao J, Wang Q and Zheng J: Interference with the expression of $\beta$-catenin reverses cisplatin resistance in A2780/DDP cells and inhibits the progression of ovarian cancer in mouse model. DNA Cell Biol 34: 55-62, 2015.

117. Xia Y, He Z, Liu B, Wang P and Chen Y: Downregulation of Meg3 enhances cisplatin resistance of lung cancer cells through activation of the WNT/ $\beta$-catenin signaling pathway. Mol Med Rep 12: 4530-4537, 2015.

118. Nagaraj AB, Joseph P, Kovalenko O, Singh S, Armstrong A, Redline R, Resnick K, Zanotti K, Waggoner S and DiFeo A: Critical role of Wnt/ $\beta$-catenin signaling in driving epithelial ovarian cancer platinum resistance. Oncotarget 6: 23720-23734, 2015.

119. Kim YH, Kim G, Kwon CI, Kim JW, Park PW and Hahm KB: TWIST1 and SNAI1 as markers of poor prognosis in human colorectal cancer are associated with the expression of ALDH1 and TGF- $\beta 1$. Oncol Rep 31: 1380-1388, 2014.
120. Yu H, Jin GZ, Liu K, Dong H, Yu H, Duan JC, Li Z, Dong W, Cong WM and Yang JH: Twist 2 is a valuable prognostic biomarker for colorectal cancer. World J Gastroenterol 19: 2404-2411, 2013.

121. Di Renzo MF, Olivero M, Giacomini A, Porte H, Chastre E, Mirossay L, Nordlinger B, Bretti S, Bottardi S, Giordano S, et al: Overexpression and amplification of the met/HGF receptor gene during the progression of colorectal cancer. Clin Cancer Res 1: 147-154, 1995.

122. Mao W, Irby R, Coppola D, Fu L, Wloch M, Turner J, Yu H, Garcia R, Jove R and Yeatman TJ: Activation of c-Src by receptor tyrosine kinases in human colon cancer cells with high metastatic potential. Oncogene 15: 3083-3090, 1997.

123. Zeng Z, Weiser MR, D'Alessio M, Grace A, Shia J and Paty PB: Immunoblot analysis of c-Met expression in human colorectal cancer: Overexpression is associated with advanced stage cancer. Clin Exp Metastasis 21: 409-417, 2004.

124. Zeng ZS, Weiser MR, Kuntz E, Chen CT, Khan SA, Forslund A, Nash GM, Gimbel M, Yamaguchi Y, Culliford AT IV, et al: c-Met gene amplification is associated with advanced stage colorectal cancer and liver metastases. Cancer Lett 265: 258-269, 2008.

125. Osada S, Matsui S, Komori S, Yamada J, Sanada Y, Ihawa A, Tanaka Y, Tokuyama Y, Okumura N, Nonaka K, et al: Effect of hepatocyte growth factor on progression of liver metastasis in colorectal cancer. Hepatogastroenterology 57: 76-80, 2010.

126. Matsui S, Osada S, Tomita H, Komori S, Mori R, Sanada Y, Takahashi T, Yamaguchi K and Yoshida K: Clinical significance of aggressive hepatectomy for colorectal liver metastasis, evaluated from the HGF/c-Met pathway. Int J Oncol 37: 289-297, 2010.

127. Sun YL, Liu WD, Ma GY, Gao DW, Jiang YZ, Liu Q and Du JJ: Expression of HGF and Met in human tissues of colorectal cancers: Biological and clinical implications for synchronous liver metastasis. Int J Med Sci 10: 548-559, 2013.

128. Abou-Bakr AA and Elbasmi A: c-MET overexpression as a prognostic biomarker in colorectal adenocarcinoma. Gulf J Oncolog 1: 28-34, 2013.

129. Sueta A, Yamamoto Y, Yamamoto-Ibusuki M, Hayashi M, Takeshita T, Yamamoto S, Omoto Y and Iwase H: Differential role of MACC1 expression and its regulation of the HGF/cMet pathway between breast and colorectal cancer. Int J Oncol 46: 2143-2153, 2015.

130. Pichorner A, Sack U, Kobelt D, Smith J, Walther W, Schlag PM and Stein U: In vivo imaging of MACC1 induced metastasis formation in a xenograft mouse model based on an IRES-vector harboring the reporter luciferase and the gene MACC1: PO125. Onkologie 33: 65, 2010. 